\title{
Synthesis and photophysical properties of novel benzophospholo[3,2-b]indole derivatives
}

\author{
Mio Matsumura ${ }^{1}$, Mizuki Yamada ${ }^{1}$, Atsuya Muranaka ${ }^{*}$, Misae Kanai ${ }^{2}$, Naoki Kakusawa ${ }^{3}$, \\ Daisuke Hashizume $^{4}$, Masanobu Uchiyama ${ }^{2,5}$ and Shuji Yasuike ${ }^{* 1}$
}

\section{Letter}

\section{Address:}

${ }^{1}$ School of Pharmaceutical Sciences, Aichi Gakuin University, 1-100 Kusumoto-cho, Chikusa-ku, Nagoya 464-8650, Japan, ${ }^{2}$ Elements Chemistry Laboratory, RIKEN, and Advanced Elements Chemistry Research Team, RIKEN Center for Sustainable Resource Science (CSRS), Wako 351-0198, Japan, ${ }^{3}$ Faculty of Pharmaceutical Sciences, Hokuriku University, Ho-3 Kanagawa-machi, Kanazawa 920-1181, Japan, ${ }^{4}$ Materials Characterization Support Unit, RIKEN Center for Emergent Matter Science (CEMS), Wako 351-0198, Japan and ${ }^{5}$ Graduate School of Pharmaceutical Sciences, The University of Tokyo, Tokyo 113-0033, Japan

Email:

Atsuya Muranaka* - atsuya-muranaka@riken.jp; Shuji Yasuike* -

s-yasuik@dpc.agu.ac.jp

* Corresponding author

Keywords:

benzophospholo[3,2-b]indole; DFT calculation; molecular structure; phosphole derivatives; photophysical property

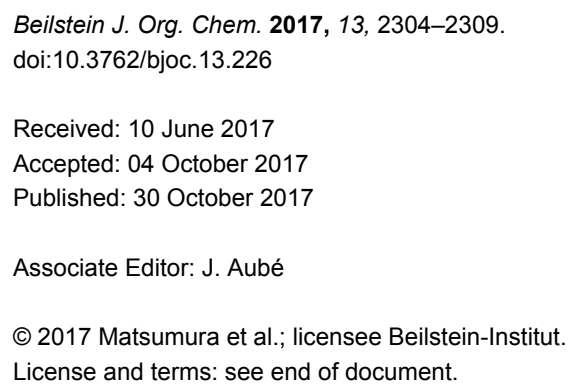

\begin{abstract}
The parent benzophospholo[3,2-b]indole was prepared by the reaction of dichlorophenylphosphine with a dilithium intermediate, which was prepared in two steps from 2-ethynyl- $N, N$-dimethylaniline. Using the obtained benzophosphole-fused indole as a common starting material, simple modifications were carried out at the phosphorus center of the phosphole, synthesizing various functionalized analogs. The X-ray structure analysis of trivalent phosphole and phosphine oxide showed that the fused tetracyclic moieties are planar. The benzophosphole-fused indoles, such as phosphine oxide, phospholium salt, and borane complex, exhibited strong photoluminescence in dichloromethane $(\Phi=67-75 \%)$.
\end{abstract}

\section{Introduction}

The chemistry of phospholes, fully unsaturated five-membered heterocyclic rings containing a phosphorus element, has drawn much attention in terms of the development of synthetic methods and elucidation of its spectroscopic properties for applications in organic field-effect transistors (OFETs) and lumi- nescent materials [1-9]. The phosphorous atom of trivalent phosphorus compounds has a high chemical reactivity. Therefore, several reactions on the phosphorus atom such as oxidation, alkylation, and coordination to a Lewis acid can produce the corresponding phosphole derivatives with different elec- 
tronic properties [10-17]. Phosphole-based ladder-type $\pi$-conjugated heteroacenes were shown to exhibit a high charge mobility and/or fluorescence quantum yields [18-24]. For example, dibenzo-fused phospholo[3,2- $b]$ phosphole dioxides (Figure 1A) $[25,26]$ and benzophosphole-fused tetracyclic heteroacenes, containing boron (B) [27-29], silicon ( $\mathrm{Si}$ ) [30], oxygen (O) [31], and sulfur (S) [32-34] (Figure 1B), were synthesized and their physical properties were studied. However, to the best of our knowledge, the synthesis of benzophospholefused indole derivatives as tetracyclic heteroacenes has not been reported. In 2015, Lu et al. reported the synthesis of only one phosphole and indole-fused pentacyclic heteroacene [35].

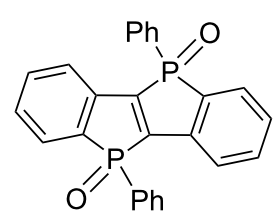

A

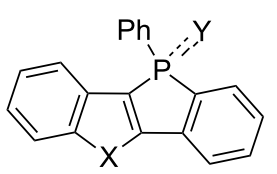

$\mathrm{X}=\mathrm{BMes}_{2}, \mathrm{SiMe}_{2}, \mathrm{O}, \mathrm{S}$ $\mathrm{Y}=\mathrm{O}, \mathrm{Me}, \mathrm{Ph}$
Figure 1: Phosphole-based tetracyclic heteroacenes.
Recently, we reported simple and efficient synthetic routes to benzothiophene-fused benzoheteroles containing the group 15 and 16 elements using the ring-closing reaction of dilithium compounds with electrophiles bearing heteroatoms [36]. In continuation of our research, we were interested in the synthesis, molecular structure, and physicochemical properties of the parent benzophosphole-fused indole derivative and its various functionalized analogs such as the corresponding phosphine oxide, phosphonium salt, and borane-phosphine complex.

\section{Results and Discussion}

The synthesis of the parent tetracyclic molecule 10-phenyl[1]benzophospholo[3,2-b]- $N$-methylindole (3), is shown in Scheme 1 . The key precursor 2 was synthesized by $\mathrm{I}_{2}$-mediated electrophilic cyclization of 2-ethynyl- $N, N$-dimethylaniline $\mathbf{1}$ [36,37]. Treatment of compound $\mathbf{2}$ with $n$-butyllithium in anhydrous THF at $-78{ }^{\circ} \mathrm{C}$ and subsequently with $\mathrm{PhPCl}_{2}$ resulted in ring closure, affording the desired benzophospholo[3,2$b$ ]indole 3 in $66 \%$ yield.

Then, the chemical modification of the phosphorus atom of $\mathbf{3}$ was carried out and the results are shown in Scheme 2. The<smiles>CN(C)c1ccccc1C#Cc1ccccc1Br</smiles>

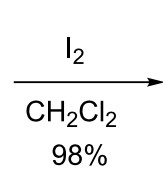

$98 \%$

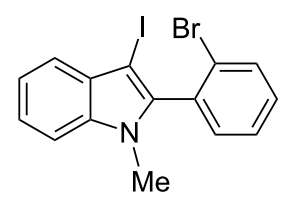

2

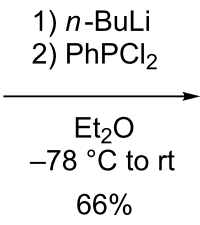

$66 \%$

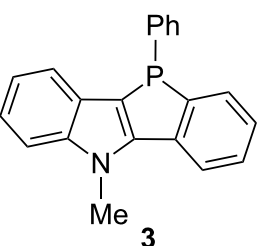

3

Scheme 1: Synthesis of benzophospholo[3,2-b]indole 3.<smiles>Cn1c2ccccc2c2c(P(=O)(c3ccccc3)c3ccccc3)cccc21</smiles><smiles>C[18OH]</smiles>

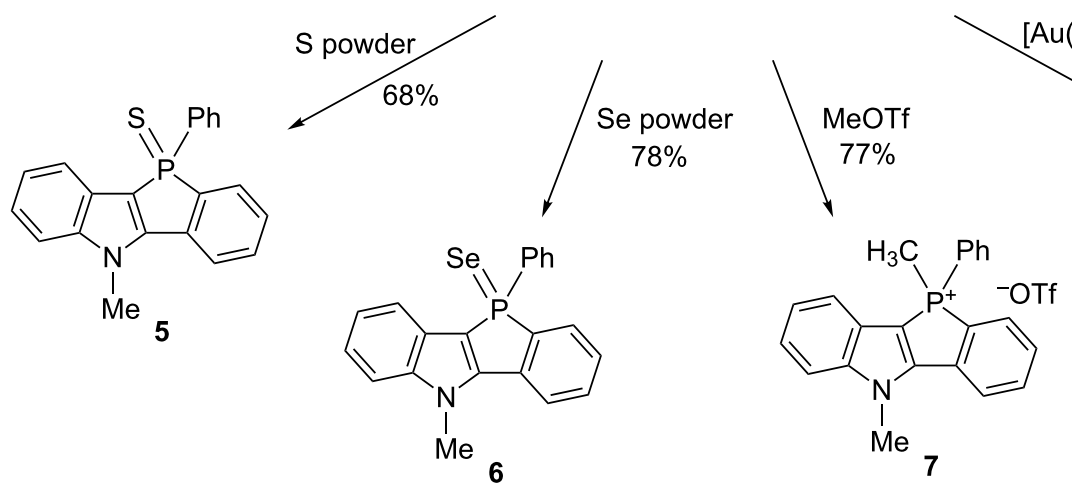

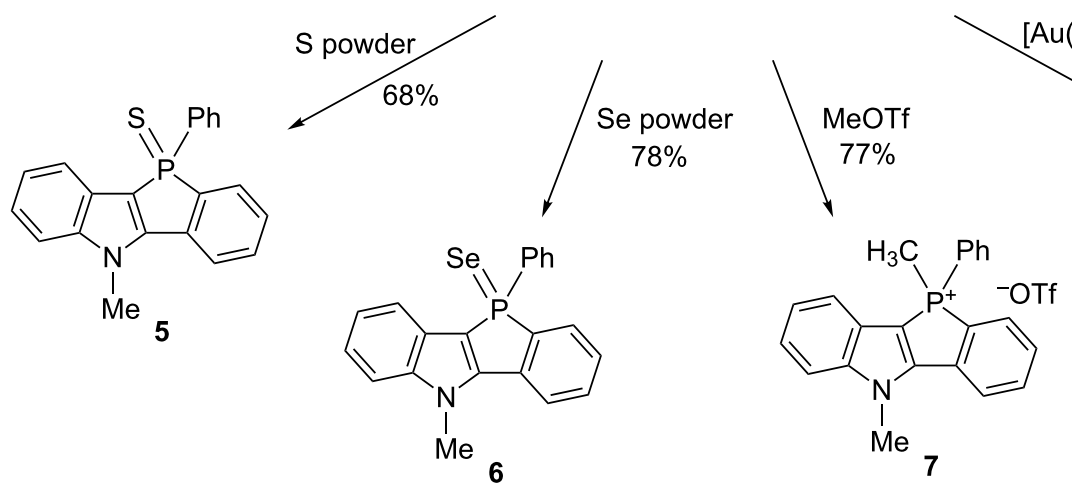<smiles></smiles>

3

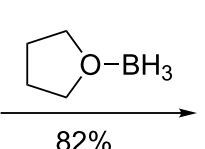<smiles>[B][PH]1(c2ccccc2)C2=CC=C(P)C2=C2C1=CN(C)c1ccccc12</smiles> 
treatment of $\mathbf{3}$ with hydrogen peroxide, elemental sulfur, and elemental selenium afforded the corresponding phosphine oxide $\mathbf{4}$, sulfide $\mathbf{5}$, and selenide $\mathbf{6}$, respectively. The reaction of $\mathbf{3}$ with methyl triflate afforded phospholium triflate 7 . Phosphole $\mathbf{3}$ was treated with chloro(dimethyl sulfide)gold in $\mathrm{CH}_{2} \mathrm{Cl}_{2}$, resulting in P-complexation and thus affording the gold complex $\mathbf{8}$. The borane complex 9 was readily prepared from $\mathbf{3}$ by treating with borane in THF.

The molecular structures of compounds 3-9 were confirmed by elemental and spectral analyses $\left({ }^{1} \mathrm{H},{ }^{13} \mathrm{C}\right.$, and ${ }^{31} \mathrm{P}$ NMR, MS, and IR). The ${ }^{31} \mathrm{P}$ NMR spectra show the typical low-field shift (4: $\delta=22.0,5: \delta=27.0,6: \delta=11.0,7: \delta=6.0 \mathrm{ppm}$ ) relative to the parent compound 3 ( $\delta=-29.1 \mathrm{ppm})$. The corresponding ${ }^{31} \mathrm{P}$ NMR signals of gold and boron complexes $\mathbf{8}$ and 9 were observed at $\delta=6.0$ and $11.5 \mathrm{ppm}$, respectively. These results show that the electronic nature of the phosphorus atoms is similar to that of the oxidized species 4-7 $(\delta=6.0-27.0 \mathrm{ppm})$. In the IR spectrum of $\mathbf{4}$ in $\mathrm{KBr}$, a strong absorption for $\mathrm{P}=\mathrm{O}$ stretching vibration at $1188 \mathrm{~cm}^{-1}$ was observed. Figure 2 shows the $\mathrm{X}$-ray crystal structures of the benzophospholo[3,2-b]indoles 3 and phosphine oxide 4 . Selected bond lengths and angles are listed in Table 1. Figure 2 clearly shows that the tetracyclic skeletons are planar. The mean deviations are $0.022 \AA$ for 3, and $0.040 \AA$ and $0.059 \AA$ for two independent molecules in the unit cell of compound 4, comparable to those of benzophosphole-fused tetracyclic heteroacenes $(0.016-0.057 \AA)$ [26,29,30,33]. The sums of the bond angles around the nitrogen atom were $359.98^{\circ}$ for 3 , and $360.02^{\circ}$ and $359.99^{\circ}$ for 4 . In contrast, these angles around the phosphorus atom were $291.05^{\circ}$ for 3 , and $305.46^{\circ}$ and $304.75^{\circ}$ for 4 . These facts indicate that the nitrogen atoms are $\mathrm{sp}^{2}$-hybridized, and the phosphorus center adopts pyramidal for $\mathbf{3}$ and tetrahedral geometry for $\mathbf{4}$.

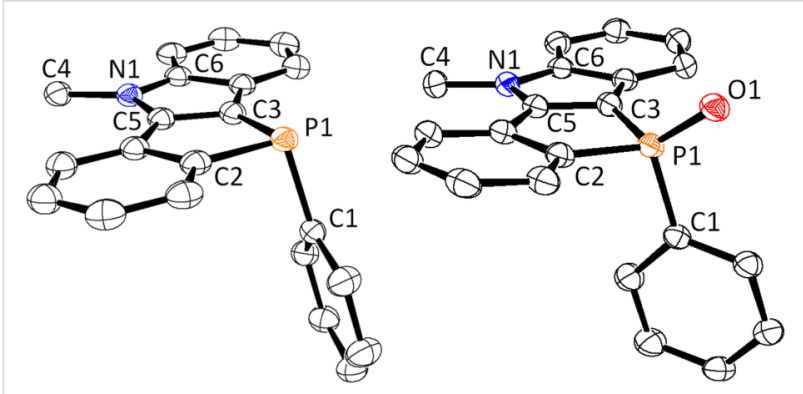

Figure 2: ORTEP drawing of compound 3 (left) and 4 (right) with $50 \%$ probability. All hydrogen atoms are omitted for clarity. One of two geometries in the unit cell was drawn for 4.

The photophysical properties of the benzophospholo[3,2$b$ ]indoles were evaluated using UV absorption and fluorescence spectroscopy in $\mathrm{CH}_{2} \mathrm{Cl}_{2}$. The spectra are shown in Figure 3, and the photophysical data are shown in Table 2. The
Table 1: Selected bond length and angles.

3

4

\begin{tabular}{lll}
\hline Bond length $[\AA]$ & & \\
\hline $\mathrm{P} 1-\mathrm{C} 1$ & $1.8467(12)$ & $1.8108(12)$ \\
$\mathrm{P} 1-\mathrm{C} 2$ & $1.8459(14)$ & $1.8215(13)$ \\
$\mathrm{P} 1-\mathrm{C} 3$ & $1.7958(12)$ & $1.7668(12)$ \\
$\mathrm{P} 1-\mathrm{O} 1$ & & $1.4897(9)$ \\
$\mathrm{N} 1-\mathrm{C} 4$ & $1.4533(16)$ & $1.4642(16)$ \\
$\mathrm{N} 1-\mathrm{C} 5$ & $1.3765(14)$ & $1.3679(16)$ \\
$\mathrm{N} 1-\mathrm{C} 6$ & $1.3869(17)$ & $1.388(2)$ \\
\hline
\end{tabular}

Bond angles $\left[{ }^{\circ}\right]$

\begin{tabular}{lll}
\hline C4-N-C5 & $127.05(11)$ & $127.33(11)$ \\
C4-N-C6 & $125.16(10)$ & $124.71(12)$ \\
C5-N-C6 & $107.77(10)$ & $107.77(11)$ \\
C1-P-C2 & $99.13(5)$ & $106.78(6)$ \\
C1-P-C3 & $102.94(5)$ & $107.01(6)$ \\
C2-P-C3 & $88.97(6)$ & $91.67(6)$ \\
O1-P1-C3 & & $121.14(6)$ \\
O1-P1-C1 & & $110.64(6)$ \\
O1-P1-C2 & & $117.52(6)$
\end{tabular}

functionalized phosphole derivatives 4-8 showed absorption maxima $\left(\lambda_{\text {abs }}\right)$ at $299-307 \mathrm{~nm}$ and a broad absorption at $\approx 355 \mathrm{~nm}$. In contrast, parent phosphole 3 showed narrow absorption peaks at 320,343 , and $357 \mathrm{~nm}$. Additionally, these compounds exhibited very little solvent dependence (see Supporting Information File 1, Figure S2). Phosphine oxide 4 exhibited blue fluorescence with the maximum emission $\left(\lambda_{\mathrm{em}}\right)$ at $450 \mathrm{~nm}$. The quantum yield $(\Phi=75 \%)$ was high, comparable to that of phosphole and indole-fused pentacyclic heteroacene ( $\Phi=70 \%$ ) [35]. On the other hand, a low fluorescence intensity was observed for phosphine sulfide $\mathbf{5}$ and selenide 6 ( $\Phi=1 \%$ and $0.3 \%$, respectively). Quenching of fluorescence emission due to a soft sulfur substituent has been reported for several phosphine sulfide $(\mathrm{P}=\mathrm{S})$ compounds

Table 2: Absorption and fluorescence spectroscopy data.
\begin{tabular}{lllll}
${ }^{\mathrm{a}}$ \\
& $\lambda_{\max }[\mathrm{nm}]$ & & $\lambda_{\mathrm{em}}[\mathrm{nm}]^{\mathrm{b}}$ & $\Phi[\%]^{\mathrm{b}}$ \\
\hline $\mathbf{3}$ & 321 & 343 & 420 & $5.3 \%$ \\
$\mathbf{4}$ & 306 & $355^{\mathrm{c}}$ & 450 & $75 \%$ \\
$\mathbf{5}$ & 299 & $355^{\mathrm{c}}$ & 446 & $1.0 \%$ \\
$\mathbf{6}$ & 307 & & 450 & $0.3 \%$ \\
$\mathbf{7}$ & 304 & & 465 & $67 \%$ \\
$\mathbf{8}$ & 307 & $355^{\mathrm{c}}$ & 437 & $11 \%$ \\
$\mathbf{9}$ & 306 & $350^{\mathrm{c}}$ & 425 & $75 \%$ \\
\hline
\end{tabular}

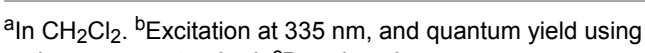
anthracene as standard. 'Broad peak. 

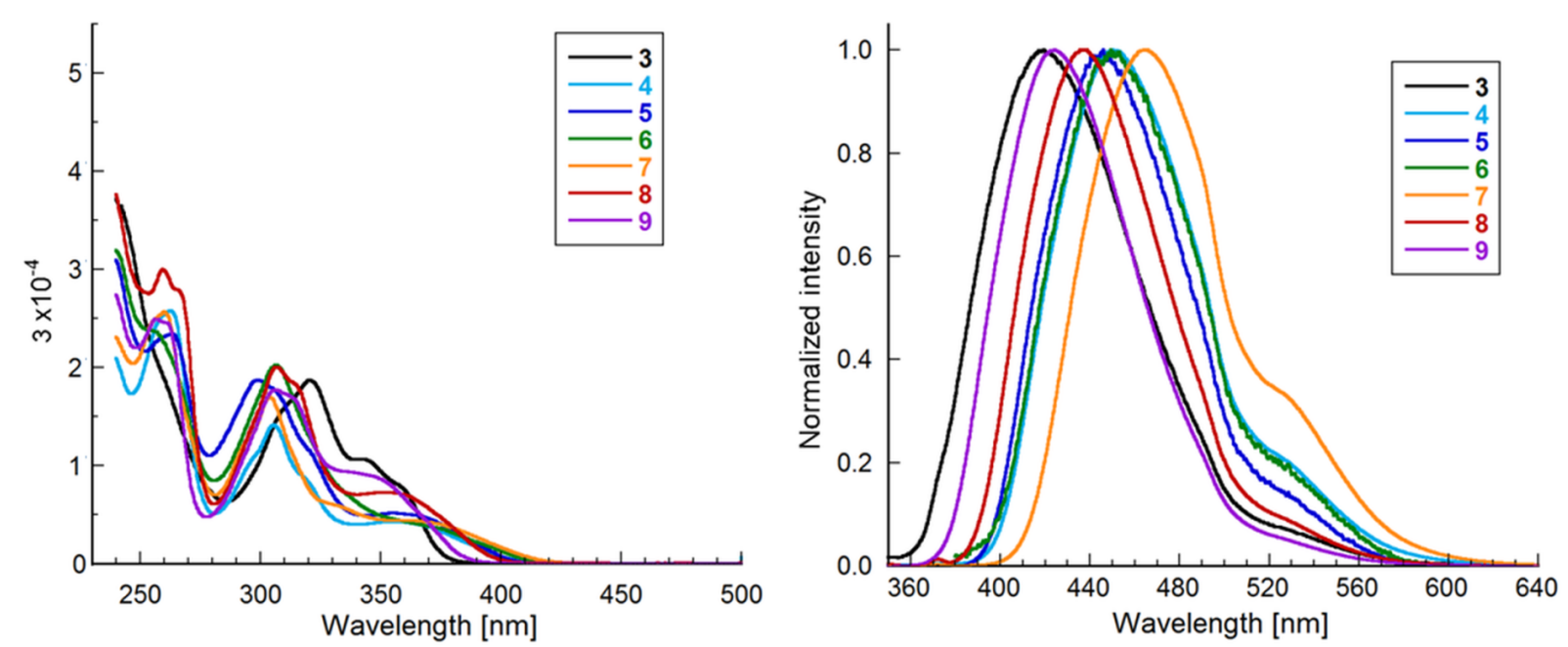

Figure 3: UV-vis absorption (left) and normalized fluorescence emission (right, excitation at $335 \mathrm{~nm}$ ) spectra in $\mathrm{CH}_{2} \mathrm{Cl}_{2}$.

$[10,15,17,20]$. The cationic phospholium 7 exhibited green fluorescence $\left(\lambda_{\mathrm{em}}=465 \mathrm{~nm}\right)$ with the largest red shift of this series of phospholes owing to the cationic nature of the phosphorus atom, providing particularly strong electron-accepting properties. This red shift related to methylation of a phosphorus atom is in line with other earlier studies $[10,18,33]$. The fluorescence intensity of 7 ( $\Phi=67 \%$ ) was as strong as that of phosphine oxide 4 . The gold and boron complexes ( 8 and $\mathbf{9}$, respectively) showed contrasting fluorescence properties with respect to the intensity. Complex 9 exhibited a high quantum yield $(\Phi=75 \%)$, while complex 8 exhibited a weak emission
( $\Phi=11 \%$ ). In these fluorescence spectra of compounds 4-7, a vibronic band was detected as a shoulder peak around $530 \mathrm{~nm}$. In the case of phosphonium cation 7 , the corresponding vibronic band was seen in the absorption spectrum at $330-340 \mathrm{~nm}$.

Density functional theory (DFT) calculations [38] were carried out at the B3LYP/LanL2DZ level of theory. The HOMO and LUMO energies of the selected compounds are given in Table 3. For fluorescent compounds 3, 4, 7, and 9, the HOMO and LUMO correspond to the $\pi$ and $\pi^{*}$ orbitals of the benzophospholoindole skeletons, respectively (Figure 4). Both<smiles>Cn1c2ccccc2c2c3ccccc3p(-c3ccccc3)c21</smiles>

3

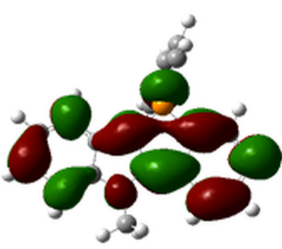<smiles>Cn1c2c(c3ccccc31)P(=O)(c1ccccc1)c1ccccc1-2</smiles>

4
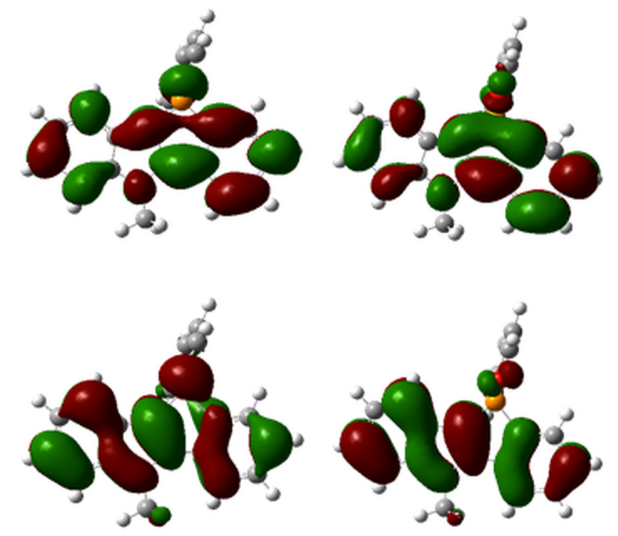
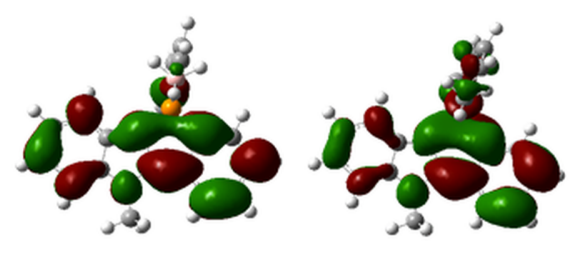<smiles>Cn1c2c(c3ccccc31)P(P)(P)(c1ccccc1)c1ccccc1-2</smiles>

7<smiles></smiles>
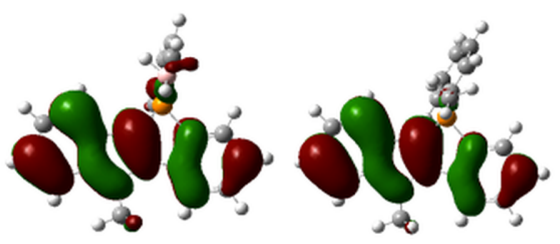

Figure 4: The spatial plots of the HOMO and LUMO of compounds 3, 4, 7 and 9. The calculations were performed at the level of B3LYP/LanL2DZ. 
Table 3: Calculated HOMO and LUMO levels of phospholes.

\begin{tabular}{lll} 
Compound & HOMO $[\mathrm{eV}]^{\mathrm{a}}$ & LUMO $[\mathrm{eV}]^{\mathrm{a}}$ \\
\hline $\mathbf{3}$ & -5.34 & -1.25 \\
$\mathbf{4}$ & -5.75 & -1.74 \\
$\mathbf{5}$ & -5.54 & -1.78 \\
$\mathbf{6}$ & -5.27 & -1.79 \\
$\mathbf{7}^{\mathrm{b}}$ & -8.82 & -5.00 \\
$\mathbf{9}$ & -5.70 & -1.62 \\
\hline
\end{tabular}

${ }^{a} D F T$ calculation at the level of B3LYP/LanL2DZ. ${ }^{b}$ Cation part only.

the HOMO and LUMO energy levels in the functionalized phosphole derivatives $\mathbf{4}$ and $\mathbf{9}$ are lower than the parent phosphole 3 owing to the increased electron deficiency of the phosphorus center. Because of the cationic nature of the phosphorus center, the energy levels in cationic phospholium 7 are significantly stabilized. In contrast to the fluorescent phospholes,

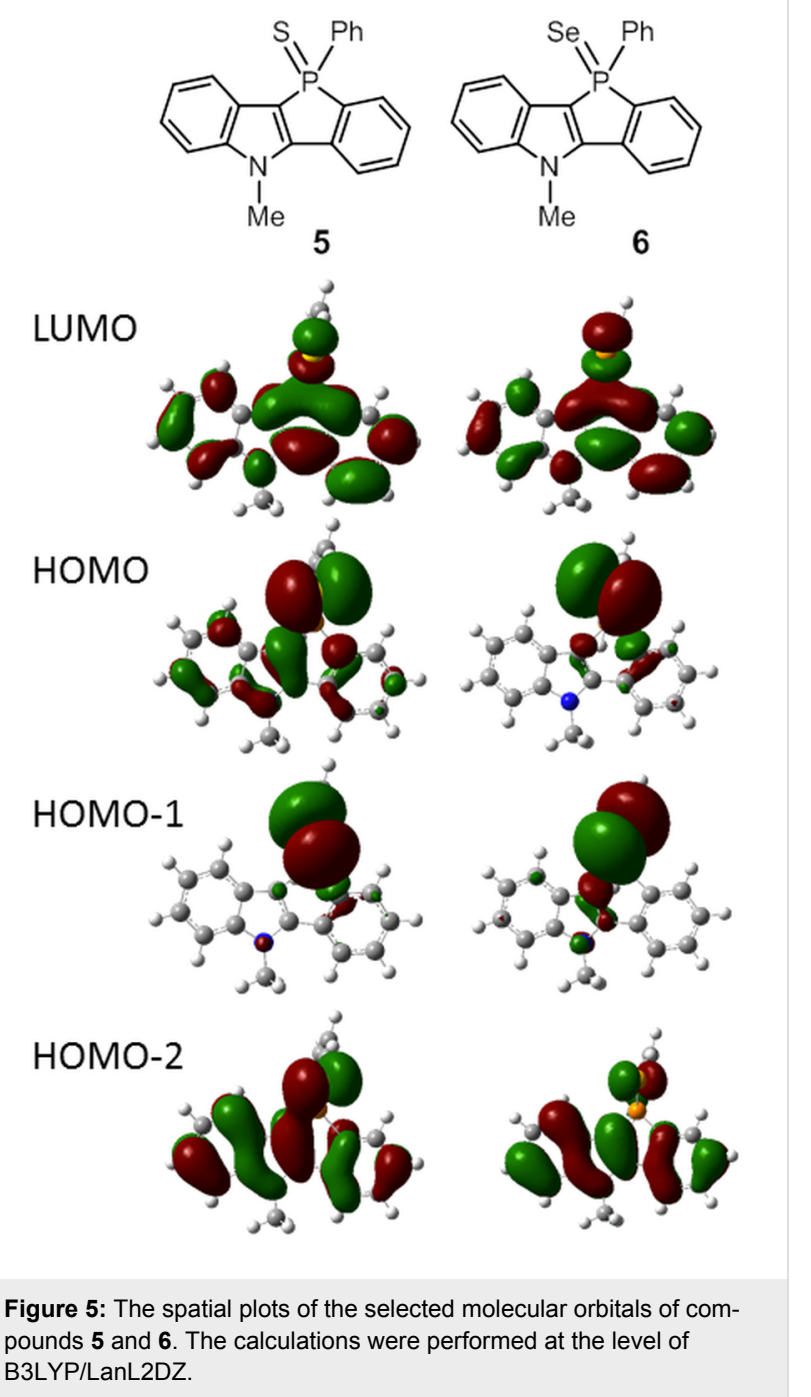

calculations show that the HOMO and HOMO-1 of nonfluorescent phosphole sulfide $\mathbf{5}$ and selenide $\mathbf{6}$ have a large contribution from the lone-pair orbitals on the $\mathrm{S}$ and $\mathrm{Se}$ atoms, respectively, and the HOMO-2 is delocalized over the conjugated $\pi$-system (Figure 5). According to the time-dependent DFT calculations for $\mathbf{5}$ and $\mathbf{6}$, the $\mathrm{S}_{0} \rightarrow \mathrm{S}_{1}$ transitions are mainly dominated by the dipole-forbidden HOMO-LUMO (lp- $\left.\pi^{*}\right)$ transition; this may be associated with the low fluorescence quantum yields.

\section{Conclusion}

A series of novel indole-fused phospholes were synthesized by simple chemical modifications at the trivalent phosphorus center. These organophosphorus compounds generated a whole series of derivatives from only one precursor. The X-ray crystal analysis of benzophospholo[3,2- $b]$ indoles showed that the nitrogen atoms are $\mathrm{sp}^{2}$ hybridized and the phosphorus atoms adopt pyramidal and tetrahedral geometry. A significant characteristic of the benzophosphole-fused indole derivatives is that the corresponding phosphine oxide, the phospholium salt, and the borane complex showed a high fluorescence emission. Further investigations are underway to develop functional materials including electronic devices and evaluate the physicochemical properties of these compounds by synthetic, theoretical, and spectroscopic studies.

\section{Supporting Information}

\section{Supporting Information File 1}

Experimental details, characterization data, and NMR spectra of all new compounds.

[http://www.beilstein-journals.org/bjoc/content/ supplementary/1860-5397-13-226-S1.pdf]

\section{Acknowledgements}

This research was supported by a research grant from the Institute of Pharmaceutical Life Sciences, Aichi Gakuin University and Hokuriku University. The DFT calculations were performed on the RIKEN Integrated Cluster of Clusters (RICC) and HOKUSAI GreatWave. We gratefully acknowledge the Advanced Center for Computing and Communication, RIKEN for providing computational resources.

\section{References}

1. Aitken, R. A. Sci. Synth. 2001, 10, 789-808.

2. Mathey, F. Sci. Synth. 2002, 9, 553-600.

3. Hissler, M.; Dyer, P. W.; Réau, R. Coord. Chem. Rev. 2003, 244, 1-44. doi:10.1016/S0010-8545(03)00098-5

4. Baumgartner, T.; Réau, R. Chem. Rev. 2006, 106, 4681-4727. doi:10.1021/cr040179m 
5. Hobbs, M. G.; Baumgartner, T. Eur. J. Inorg. Chem. 2007, 3611-3628. doi:10.1002/ejic.200700236

6. Matano, Y.; Imahori, H. Org. Biomol. Chem. 2009, 7, 1258-1271. doi:10.1039/b819255n

7. Matano, Y.; Nakabuchi, T.; Imahori, H. Pure Appl. Chem. 2010, 82, 583-593. doi:10.1351/PAC-CON-09-08-05

8. Zagidullin, A. A.; Bezkishko, I. A.; Miluykov, V. A.; Sinyashin, O. G. Mendeleev Commun. 2013, 23, 117-130. doi:10.1016/j.mencom.2013.05.001

9. Duffy, M. P.; Delaunay, W.; Bouit, P.-A.; Hissler, M. Chem. Soc. Rev. 2016, 45, 5296-5310. doi:10.1039/C6CS00257A

10. Chan, J. C.-H.; Lam, W. H.; Wong, H.-L.; Wong, W.-T.; Yam, V. W.-W. Angew. Chem., Int. Ed. 2013, 52, 11504-11508. doi:10.1002/anie.201304827

11. Ren, Y.; Baumgartner, T. Chem. - Asian J. 2010, 5, 1918-1929. doi:10.1002/asia.201000196

12. Dienes, Y.; Durben, S.; Kárpáti, T.; Neumann, T.; Englert, U.; Nyulászi, L.; Baumgartner, T. Chem. - Eur. J. 2007, 13, 7487-7500. doi:10.1002/chem.200700399

13. Durben, S.; Dienes, Y.; Baumgartner, T. Org. Lett. 2006, 8, 5893-5896. doi:10.1021/ol062580w

14. Dienes, Y.; Eggenstein, M.; Neumann, T.; Englert, U.; Baumgartner, T. Dalton Trans. 2006, 1424-1433. doi:10.1039/B509277A

15. Baumgartner, T.; Bergmans, W.; Kárpáti, T.; Neumann, T.; Nieger, M.; Nyulászi, L. Chem. - Eur. J. 2005, 11, 4687-4699. doi:10.1002/chem.200500152

16. Baumgartner, T.; Neumann, T.; Wirges, B. Angew. Chem., Int. Ed. 2004, 43, 6197-6201. doi:10.1002/anie.200461301

17. He, X.; Woo, A. Y. Y.; Borau-Garcia, J.; Baumgartner, T. Chem. - Eur. J. 2013, 19, 7620-7630. doi:10.1002/chem.201204375

18. Dienes, Y.; Eggenstein, M.; Kárpáti, T.; Sutherland, T. C.; Nyulászi, L.; Baumgartner, T. Chem. - Eur. J. 2008, 14, 9878-9889. doi:10.1002/chem.200801549

19. Fukazawa, A.; Yamaguchi, S. Chem. - Asian J. 2009, 4, 1386-1400. doi:10.1002/asia.200900179

20. Fukazawa, A.; Ichihashi, Y.; Kosaka, Y.; Yamaguchi, S. Chem. - Asian J. 2009, 4, 1729-1740. doi:10.1002/asia.200900303

21. Wang, C.; Fukazawa, A.; Taki, M.; Sato, Y.; Higashiyama, T.; Yamaguchi, S. Angew. Chem., Int. Ed. 2015, 54, 15213-15217. doi:10.1002/anie.201507939

22. Matano, Y.; Motegi, Y.; Kawatsu, S.; Kimura, Y. J. Org. Chem. 2015, 80, 5944-5950. doi:10.1021/acs.joc.5b00541

23. Hibner-Kulicka, P.; Joule, J. A.; Skalik, J.; Bałczewski, P. RSC Adv. 2017, 7, 9194-9236. doi:10.1039/C6RA26333J

24. Adler, R. A.; Wang, C.; Fukazawa, A.; Yamaguchi, S. Inorg. Chem. 2017, 56, 8718-8725. doi:10.1021/acs.inorgchem.7b00658

25. Fukazawa, A.; Murai, T.; Li, L.; Chen, Y.; Yamaguchi, S. C. R. Chim. 2010, 13, 1082-1090. doi:10.1016/j.crci.2010.04.021

26. Fukazawa, A.; Hara, M.; Okamoto, T.; Son, E.-C.; Xu, C. H.; Tamao, K.; Yamaguchi, S. Org. Lett. 2008, 10, 913-916. doi:10.1021/ol7030608

27. Fukazawa, A.; Yamaguchi, E.; Ito, E.; Yamada, H.; Wang, J.; Irle, S.; Yamaguchi, S. Organometallics 2011, 30, 3870-3879. doi:10.1021/om200453w

28. Fukazawa, A.; Yamada, H.; Sasaki, Y.; Akiyama, S.; Yamaguchi, S. Chem. - Asian J. 2010, 5, 466-469. doi:10.1002/asia.200900517

29. Fukazawa, A.; Yamada, H.; Yamaguchi, S. Angew. Chem., Int. Ed. 2008, 47, 5582-5585. doi:10.1002/anie.200801834

30. Xu, Y.; Wang, Z.; Gan, Z.; Xi, Q.; Duan, Z.; Mathey, F. Org. Lett. 2015, 17, 1732-1734. doi:10.1021/acs.orglett.5b00598
31. Takahashi, M.; Nakano, K.; Nozaki, K. J. Org. Chem. 2015, 80, 3790-3797. doi:10.1021/jo502889r

32. Weymiens, W.; Zaal, M.; Slootweg, J. C.; Ehlers, A. W.; Lammertsma, K. Inorg. Chem. 2011, 50, 8516-8523. doi:10.1021/ic201116p

33. Ren, Y.; Baumgartner, T. J. Am. Chem. Soc. 2011, 133, 1328-1340. doi:10.1021/ja108081b

34. Ren, Y.; Biegger, F.; Baumgartner, T. J. Phys. Chem. C 2013, 117, 4748-4758. doi:10.1021/jp3115012

35. Gong, P.; Ye, K.; Sun, J.; Chen, P.; Xue, P.; Yang, H.; Lu, R. RSC Adv. 2015, 5, 94990-94996. doi:10.1039/C5RA19867D

36. Matsumura, M.; Muranaka, A.; Kurihara, R.; Kanai, M.; Yoshida, K.; Kakusawa, N.; Hashizume, D.; Uchiyama, M.; Yasuike, S. Tetrahedron 2016, 72, 8085-8090. doi:10.1016/j.tet.2016.10.048

37. Mehta, S.; Waldo, J. P.; Larock, R. C. J. Org. Chem. 2009, 74, 1141-1147. doi:10.1021/jo802196r

38. Gaussian 09, Revision E.01; Gaussian, Inc.: Wallingford, CT, 2009.

\section{License and Terms}

This is an Open Access article under the terms of the Creative Commons Attribution License (http://creativecommons.org/licenses/by/4.0), which permits unrestricted use, distribution, and reproduction in any medium, provided the original work is properly cited.

The license is subject to the Beilstein Journal of Organic Chemistry terms and conditions:

(http://www.beilstein-journals.org/bjoc)

The definitive version of this article is the electronic one which can be found at: doi:10.3762/bjoc. 13.226 